\title{
THE METHODOLOGY OF ACCOMPLISHING OF ASSESSMENT OF EFFICIENCY OF REGIONAL INVESTMENT POLITICS OF THE AGRICULTURE FORMATION
}

\section{Borovik L. V.}

\section{INTRODUCTION}

To the determination of efficiency of the investment politics influence on the development of agriculture were dedicated many scientific works of such prominent scholars as: V.T. Andrijchuk, S.O. Hutkevych, M.V. Zubetsj, M.I. Kisilj, M.J. Kodensjka, P.T. Sabluk, V.P. Sytnyk and others. Taking into account particular relevance of investment resources in the development of separate branches and the improvement of their investment appeal, V.M. Grynjova, V.O. Kojuda, T.I. Lepejko, O.P. Kojuda offered to estimate the investment potential, applying the level of perceptivity that displays the significance of field in economy, sustainability of the industry to the decline of production, security of prospects of growth of its own financial resources and degrees of state support of the development of the branch.

While the estimation of investment attractiveness of the branch, V.I. Polyshakov and N.V. Tkalenko recommend assessing the market factors, the technological factors, the level of competitiveness, the raw material base, the social level of branch development, the barriers of admission and exclusion of the enterprise to the branch (Polshakova V.I. 2009) ${ }^{1}$ But the conclusions made by them relate mostly to economic and social problems. There is no modern methodology, which could give an opportunity to estimate the efficiency of agrarian investment politics depending on the cumulative impact of economic, social and ecological factors, which makes the implementation of rational management of investment processes impossible in the agrarian sector of economy. Herewith, as in previous case, are not considered natural, ecological and other important components of the investment potential that significantly influence the competitiveness of agrarian sphere (Goncharenko I.V., Tanklevska N.S. 2010) ${ }^{2}$, (Orlovskaya Y.V. $(2006)^{3}$.

${ }^{1}$ Polshakova V.I. (2009). Investment management. «Kondor». Ukraine.

${ }^{2}$ Goncharenko I.V., Tanklevska N.S. (2010). Methodical approaches to the implementation of the budgeting system at enterprises. Bulletin of Sumy National Agrarian University. 5/2 (40). 64-68. Ukraine.

${ }^{3}$ Orlovskaya Y.V. (2006). Strategy of investment management in regional development. Knowledge of Ukraine. 
To determine and justify methodical approaches to comprehensive assessment of efficiency of investment politics in the agriculture.

The modern methodical approaches do not provide the distinct reply to the estimation of the efficiency of regional investment politics of the agriculture development. This is explained by the fact that the agrarian branch is a complex system that consists of many sub-branches and is characterized by the utilization of land resources potential as the main mean of production. The land productivity is determined by the amount of received output from the unit of land area, on what influence the economic, social and ecological factors.

Till this moment among the scientists there is no common thought concerning the determination of the factors, which have the biggest influence on the formation and usage of the investment potential of the agriculture. The scholars offer different methodologies of determination of the estimation of investment appeal of the sector, but not accounted are regional peculiarities, natural, ecological and other significant components of the investment potential, which considerably influence the competitiveness of the agrarian sphere.

\section{The peculiarities of the investment politics of the regional development of the agriculture}

Considering the particular importance of investment resources in the development of separate branches and the improvement of their investment attractiveness, V. M. Grynyova, V. O. Koyuda, T. I. Lepeyko, O. P. Koyuda offered to estimate the investment potential, applying (Grinyova V.M., Koyuda V.O. 2004) $)^{4}$ :

- the level of profitability that considers all spent and their own assets, the product distribution and the expenses for its production;

- the level of prospects that displays the relevance of the branch in economy, the stability of the branch before the production recession, the prospects security of growth of their own financial resources and the levels of state support of the branch development;

- the level of investment risks that consider the level of competitiveness, the inflation steadiness of output and the level of social tension.

It is also necessary to encourage the population more actively to the investment of environmental programs (planting of trees around the water bodies and along the roads, the formation of dust protecting woodland belts, cleaning of the flood draining sewers from the garbage, the use of soil protecting technologies at the individual farms, etc.). The local authorities, Press.

${ }^{4}$ Grinyova V.M., Koyuda V.O. (2004). Finance of enterprises (2nd ed). Knowledge. 
applying the administrative leverages, should collaborate with the charity organizations and direct the funds for social needs, the improvement of life quality of population. First of all, this concerns those territories that suffer from the environmental pollution by industrial enterprises, flooding of localities, in consequence of the inefficient and unreasonable use of water resources and deforestation, the destruction of woodland belts around the water bodies. Such risky and dangerous territories are not left without the attention of big investors who do not wish to invest the funds in the agrarian industry because of the risk of shortening of planned profit. The size of ecological risk influences the amount of possible loss directly. While estimating the level of ecological risks on this or other territory, the investor defines the losses which he can get in the future. Mostly, such ecologically dangerous territories do not attract the investors and lag behind in their economic and social development. Taking this into account, the state and the regions should realize the permanent monitoring of problem territories, stimulate the utilization of ecologically safe technologies in the agriculture, invest the funds in the revitalization works, preventing the premature decommissioning of agrarian lands, carry out the social protection of population from the undesirable consequences of irresponsible intervention of a human in the nature.

Considering that the harmony of influence of the regional investment politics of the agriculture development on the economic, social and ecologic factors, the decrease of influence of investment threats and the effective formation are the base of attainment of the political aims, it is necessary to estimate its efficiency, following the next principles:

- the components of investment potential should have the characteristics typical for all forms of ownership of the subjects of the economic activity on which the economic efficiency of the branch depends the most of all;

- while analyzing the components of investment potential, it is necessary to receive the maximum of information not only about the economic and financial state of the branch but also about the social and ecologic ones;

- the components of investment potential should reveal the peculiarities of economic activity of the branch as fully as possible;

- the components of investment potential should be analyzed in the dynamics with the aim of obtaining of information which is going to indicate the changes of the state of attractiveness of the agrarian investment market;

- the analysis of components of the investment potential should form the base of measures, aimed at the increase of the level of investment attraction of the branch, the efficiency of the formation of investment potential and the improvement of the level of livelihood of the countryside citizens.

The harmony of influence of regional investment politics of the agriculture development on the formation of economic, social and ecological potentials 
will determine its effectiveness (performance). Based on the fact that the formation of investment potentials takes place on the background of threats and opportunities, and their physical indexes of measurement have different meanings and need the transfer to one-dimensional, the estimation of efficiency of regional investment politics of the agriculture development requires such sequence of tasks performance:

- the analysis of economic, social and ecological state of the branch;

- the division of investment potential to "stimulants", namely those that stimulate the development of agriculture and "destimulants", which throughout many years reduce their activity and are the threat for the agriculture development. The average meanings of these indexes (points) during the years of research are lower than those which were on the initial stage of researches;

- the rating assessment of the influence of investment politics of the agriculture development on every factor of economic, social and ecological development;

- the determination of integral assessments of the efficiency of investment politics influence on the formation of investment potential and investment climate in the agriculture;

Taking into account the above mentioned, the assessment of the efficiency of regional investment politics influence on the agriculture development will be carried out on the base of build algorithm (fig. 1), and also the combination of methodic of the rating assessment of investment potential of the branch, methodic SWOT - the analysis (for detection of opportunities of the formation of investment potential and the reduction of the level of threats) and mathematically - the geometric model of determination of integral assessments of the efficiency of regional investment politics influence on the formation of investment potential and appeal of investment climate of the agriculture.

At the first stage of our research we will apply the methodic of rating assessment of investment potential of the branch and investment threats, it provides the formation of the system of indexes according to the main directions of mission of agrarian investment politics; the mathematical processing of estimating factorial indexes; the formation of scale of determination of rating estimation of every factor of assessment; evaluation of factorial indexes for every year and for the whole term of research. While conducting of the rating assessment we will use only quantitative statistical indexes, which give the opportunity to apply the method of standardization, suggested by V.E. Shvets.

The rating assessment of every factor - is its complex characteristics, which is carried out by the analysis of components of economic, social and 
ecological state of the branch and can be estimated, using actual standardized meanings of every separate factor by ten points scale.

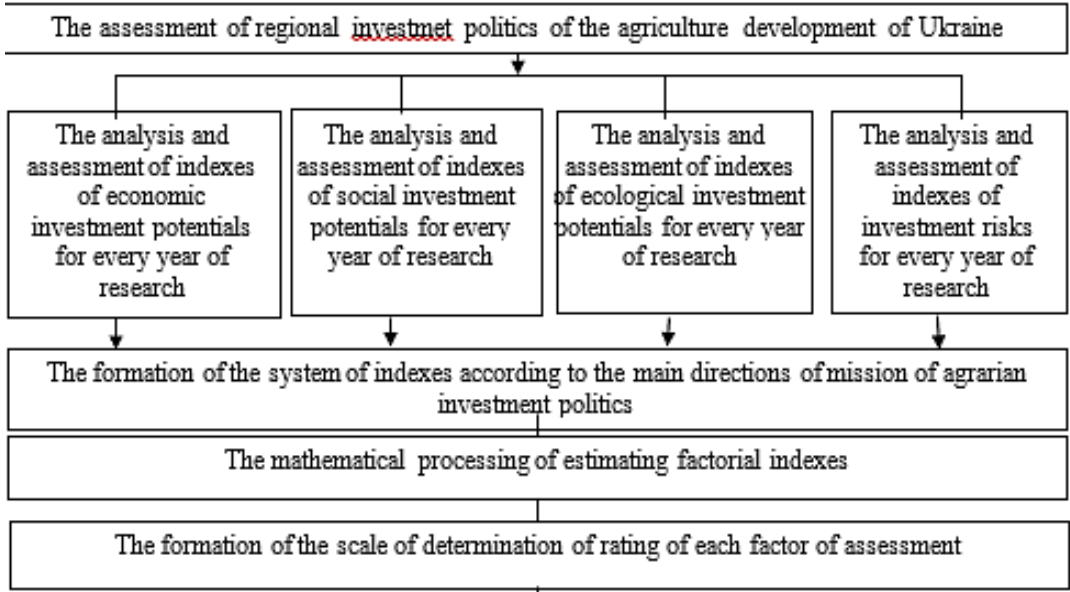

The rating assessment of factorial indexes for every year and for the entire term of research

The determination of integral coefficients of the formation of investment potentials (stimulants and destimulants)

The development of the scale of assessment of efficiency of investment politics influence on the formation of investment potential and investment climate in the agriculture

The determination of integral assessments of efficiency of investment politics influence on the formation of investment potential and investment climate in the branch, using the geometric model and the scale of assessment

The determination of general integral assessments of efficiency of investment politics influence on the formation of investment potential and investment climate in the agriculture

The conclusions about the efficiency of regional investment politics of the agriculture development of Ukraine

\section{Fig. The algorithm of determination of assessment of efficiency of regional investment politics influence on the agriculture development of Ukraine}

*Developed by the author 
Each index of standardized meaning will be estimated as low, medium and high in accordance to the determined parameters and points, which will be received by the results of conducted analytical calculations. By the analogical method, namely the method of standardization, the assessment of investment risks will be accomplished.

The point of this method consists in that at first the arithmetic mean of factorial index is found $-\mathrm{x}$, and further the root-mean-square deviation of index is determined $-\left(\mathrm{x}_{\mathrm{i}}-\mathrm{x}\right)^{2}$, where $\mathrm{x}_{i}-$ the actual meaning of $i$-factorial index (in our case the meaning of one of investment potentials). Afterwards the standardized deviation of index of the formation of investment potential usage is calculated according to the formula:

$$
\mathrm{S}=\sqrt{\frac{\sum(x i-\bar{x})^{2}}{n}},
$$

where $\mathrm{S}$ - the standardized deviation of index;

$\mathrm{n}$ - the quantity of researched objects (potentials).

While determining the standardized meaning of $i$ - factorial index $\left(\mathrm{x}^{1} i\right)$, it is necessary to use the formula:

$$
x^{1}=\frac{X i}{S}
$$

Substituting the formula (2.1) in the formula (2.2) we will receive the final formula for determination of the standardized meaning of $i$ - factorial index of the formation (usage) of investment potential:

$$
X_{i}^{1}=\frac{x i}{\sqrt{\frac{\sum(x i-\bar{x})^{2}}{n}}}
$$

The meaning of analytical index for each separate factor of the formation (usage) of investment potential will be determined as the arithmatic mean of standardized factorial indexes. Here with, the weight of indexes will not be considered, which is going to enable to prioritize and introduce to the calculations those indexes, which are necessary for the conduction of research.

After accomplishing of the assessment of formation of investment potential and reduction of the threat level, we will determine the efficiency of formation of economic, social and ecological potentials of the branch in the 
background of real opportunities and threats of the agriculture development. We will determine the efficiency of formation of investment potential of the branch, using the methodic SWOT - the analysis, which can be applied either on the level of separate regions or branches, creating the appropriate matrix. Carrying out the analysis of efficiency of formation of investment potential of the agriculture we will characterize strong points (strength), weak points (weaknesses), possibilities (opportunities) and threats (threats).

The obtained results of research give an opportunity to determine the efficiency of formation of economic, social and ecological investment potentials of the agriculture according to the formula:

$$
C e f f .=\sum^{n} \operatorname{In}: \sum^{n} I 3
$$

where Ceff. - the coefficient of efficiency of the formation of investment potentials of the branch;

$\sum^{n} I n-$ the sum of points of factorial indexes of investment potentials (stimulants) of the branch;

$\sum^{n} I 3-$ the sum of points of indexes of investment threats (destimulants) of the branch.

The parameters of assessment of the efficiency of formation of investment potential of the branch have to be:

- high level $($ Kin >1);

- medium level $(\operatorname{Kin}=1)$;

- low level (Kin <1).

At the second phase of research accomplishing, using the geometrical model and the scale of estimation, we will determine the integral assessment of the level of efficiency of the regional investment politics influence on the formation of the investment potential and investment climate of the branch in such sequence:

1. We will determine the integral coefficients of economic, social and ecological investment potentials [stimulants and destimulants (threats):

$$
\mathrm{C}=\sqrt{\mathrm{Pp}},
$$

where $\mathrm{C}$ - the integral coefficient of factorial potential;

$\mathrm{Pp}$ - the index of rating assessment of factorial potentials. 
2. We will accomplish the assessment of efficiency of investment politics influence on the formation of social, economic and ecological factorial potentials [stimulants and destimulants (threats):

$$
I e f f .=\frac{\sqrt{C P_{1} x C P_{2} x \ldots C P n}}{C T_{1} x C T_{2} x \ldots C T n},
$$

where Ieff. - the integral index of the assessment of efficiency of investment politics influence on the formation of, separately, economic, social and ecological potentials;

$C P$ - the coefficient of investment potentials - stimulants;

$C T$ - the coefficient of investment potentials - destimulants (threats).

3. The average meaning of integral index of efficiency of investment politics influence on the formation of investment potential of the agriculture will be determined according to the formula:

$$
\text { Ic.eff } .=\sqrt[3]{\text { Iec.eff .xIsoc.eff .xIecol.eff }}
$$

where Ic.eff. - the average integral index of efficiency of investment politics influence on the formation of investment potential;

Iec.eff. - the integral index of economic efficiency;

Isoc.eff. - the integral index of social efficiency;

Iecol.eff. - the integral index of ecologic efficiency.

4. The average meaning of integral index of the influence of regional investment politics of the agriculture development on the reduction of investment threats will be determined according to the formula:

$$
\text { Ia.t. }=\sqrt[3]{\text { Iec.t.xIsoc.t.xIecol.t. }},
$$

where Ia.t. - the average integral index of investment politics influence on the reduction of investment threats;

Iec.t. - the integral index of economic threats;

Isoc.t. - the integral index of social threats;

Iecol.t. - the integral index of ecologic threats.

5. The significant index of assessment of efficiency of investment politics of regional development of the agriculture is the level of the formation of investment climate. Taking into account that on the formation of investment climate influence the cumulative investment potential of economic, social and ecological factors (stimulants) and ecological threats (destimulants), we will determine this index according to the formula: 


$$
I C=\sqrt{\text { Ic.eff. }}-\sqrt{\text { Ic.t. }},
$$

where $I c$ - the integral index of the formation of investment climate;

Ic.eff. - the average integral index of investment politics influence on the formation of investment potential;

Ic.t. - the average integral index of investment politics influence on the level of investment threats.

The level of the efficiency of regional investment politics influence on the formation of investment appealing climate in the agriculture during 2010-2017 we will determine according to such scale of assessment (1):

Table 1

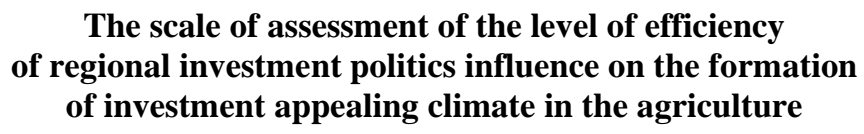

\begin{tabular}{|c|c|c|}
\hline № & $\begin{array}{c}\text { The level } \\
\text { of efficiency }\end{array}$ & $\begin{array}{c}\text { The average meaning } \\
\text { of integral index (Ic.eff.) }\end{array}$ \\
\hline 1. & High & $>0,80$ \\
\hline 2. & Medium & $0,60-0,79$ \\
\hline 3. & Low & $0,41-0,59$ \\
\hline 4. & Crisis & $0,40<$ \\
\hline
\end{tabular}

The level of efficiency of the formation of appealing investment climate is determined by:

a) high level - the integral index of the formation of investment appealing climate indicates to the reduction of the level of threats to minimal level and the growth of investment potential of the branch, which ensures high tempos of production, high level of profitability of agricultural output, competitiveness of enterprises and social standards;

b) medium level - is such a level of investment appeal of investment climate, which enables to satisfy the manufacturers' needs in investments for more than half and to ensure the steadiness of growing agriculture development of country regions, to intensify investment activity in rural area;

c) low level - is characterized by insignificant investments in the agriculture development, low competitiveness of agrarian output, insignificant capital investments in the land, low tempos of production;

d) crisis level - is characterized by insignificant volumes of floating assets of agrarian enterprises, by low level of their crediting, by the reduction of volumes of foreign investment of the agriculture, by low profitability and competitiveness of industrial structures, by low level of social standards, by considerable percentage of work force from the rural area. 
6. Accomplishing separately the assessment of investment politics influence on the formation of investment potential (Ig.eff.) and investment climate (IC), we will carry out their general integral assessment:

$$
\text { Ieff.i.i. }=\sqrt{\operatorname{Ig} . e f f . x I C} \text {, }
$$

where Ieff.i.i. - the integral index of assessment of efficiency of investment politics;

Ig.eff. - the average meaning of integral index of the formation of investment potential of the branch;

$I C$ - the integral index of assessment of the formation of investment climate.

The parameters of the assessment of efficiency of investment politics have to be:

- high level $(>1)$;

- medium level $(=1)$;

- low level $(<1)$.

Thus methodic-methodological sequence enables to estimate the influence of regional investment politics on the formation of investment potential and appealing investment climate in the agriculture gradually, to estimate the level of increase of social standards of population of the rural areas and to conduct the integral assessment of influence of regional investment politics on the development of agriculture, which according to the data of general conclusions, can be effective or ineffective. The suggested methodological and methodic approaches to the assessment of efficiency of regional investment politics of the agriculture development are based on the principles, which characterize the growth of branch and are determined by the totality of economic, social and ecological factors with consideration of threats and opportunities. The methods, which will be used in the process of research, enable to estimate the influence of investment politics on the formation of investment potentials of the branch gradually, the reduction of investment threats and to accomplish the integral assessment of efficiency of the implementation of state investment politics of the agriculture development, which is going to allow to make the general conclusion to its efficiency of influence on the development of agrarian branch.

\section{The assessment of the impact of regional investment politics on the formation and utilization of investment potential of the branch}

The extremely low level of attractiveness of the social investment potential reduces the general rating index and points out to the unsatisfactory social investment state politics in the agrarian branch of the regions. To improve such negative phenomenon is possible only through the development of 
market social infrastructure in the countryside, by the increase of salaries of workers, by the enhancement of volumes of the social assistance for those who do not have a possibility to get employed or to be engaged in the individual production.

To our point of view, one of the main assignment of the regional agrarian politics, in this difficult crisis period, should be the establishment of conditions for more intensive development of the private farms of population including also the individual rural households that, producing almost the half of agrarian output, influence significantly on the state of food security of the country on the investment attractiveness of the agriculture (Prikhodko I.P., $2004)^{5}$. Receiving the insignificant support from the country, the individual rural households, economically and socially developing, carry out the following functions: the production of agrarian output as for their own consumption and also for realization at the markets; the involvement to the process of production everyone including the retired and disabled people; the increase of the level of life of the rural population; the assistance of intensification of the use of rural lands and support of the functioning of the countryside schools, kindergartens, medical facilities and others; the creation of conditions for the reduction of prices for the agricultural output through the creation of competition for the big farms; the processing and storage of the privately produced output; the provision of services to the local population; the arrangement of "green tourism" and others.

The typical peculiarity of the individual rural households is their high level of economic development, the transfer from the subsistence farming to commercial, the utilization of opportunities of the cooperative collaboration, the usage of small mechanization and innovative technologies on the insignificant by the size plots of land that allows to receive the competitive output (Petina L.V., 2015) ${ }^{6}$.

Applying the instruments of administrative, law and economic management, the state carries out the political impact on the creation of conditions for the efficient usage of opportunities of investment resources and the decrease of the amount of threats that prevent the development of the agriculture. Enacting the appropriate laws of Ukraine, the state regulates the relations between the participants of the agrarian investment market, attempting to create the attractive investment climate in every region of the country that could positively influence the increase of competitiveness of the

${ }^{5}$ Prikhodko I.P. (2004). The efficiency of personal peasant farms. State and Regions. Series: economics and entrepreneurship. 2. 123-125.

${ }^{6}$ Petina L.V. (2015). Leasing - an innovative factor in activating investment processes in agriculture. Economics. Finances. Jurisprudence. Kyiv. 7.4-7. 
agrarian output (Petina L.V., 2010) ${ }^{7}$ and the growth of quality of livelihood of the rural population. Giving the definition of the mechanism of state management, S. V. Onyshko underlines that it is the unity of regulators with the assistance of which the social economic politics is carried out

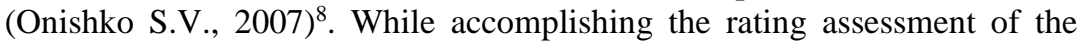
formation of regional investment potential of the agriculture, it is necessary to identify the opportunities for its increase. The indexes of the level of formation of the investment potential can be indexes of their dynamics for every year of our research in calculation per one person or per one unit of resource. Applying the method SWOT - the analysis, we will estimate the strong and weak points and then the opportunities and the threats, what is going to help to form the full opinion not only about the general level of formation of the real potential of the branch but also to detect the opportunities of its growth and reduction of the level of threats of the agriculture development and the usage of the available resource of the branch (Karnaushenko A., Petrenko V., Tanklevska N., Borovik L., \& Furdak M., 2020) ${ }^{9}$.

To the strong points are included such indexes as: the sown areas, the irrigated lands of the agrarian enterprises, the rural housing stock, the direct foreign investments, the power capacities, the number of people who studied at the general education institutions. The rating indexes of these factors are high and made 8,90 points in 2014, and the medium index for 2014-2020 made 9,22 points, in other words increased for $3,6 \%$. The insignificant increase of the rating assessment points out to the low level of formation of the main means of production. Possessing the soil of the best quality in the world and the biggest irrigated land masses in Europe, the agrarian enterprises use them irrationally. On average, during the period from 2014 till 2020 the efficiency of formation of the investment potential of the irrigated lands rose only for 3,0\%. Even in the south of Ukraine, where it is impossible to develop not only the branch of plant cultivation without irrigation, but also the animal husbandry, more than half of the irrigated lands are not used to destination. The lack of the state program for the reconstruction of irrigated lands, the reduction of production of the special technical means for the irrigation and cultivation of the irrigated lands, almost the full closure of training of such

${ }^{7}$ Petina L.V. (2010). Directions of growth of investment potential of agrarian enterprises. Tavriya Scientific Bulletin. Kherson. 81. 395-399.

${ }^{8}$ Onishko S.V. (2007). State regulation of the national economy. Irpin: National University of the State Tax Service of Ukraine.

${ }^{9}$ Karnaushenko, A., Petrenko, V., Tanklevska, N., Borovik, L., \& Furdak, M. (2020). Prospects of youth agricultural entrepreneurship in Ukraine. Agricultural and Resource Economics: International Scientific E-Journal, 6(4), 90-117. DOI: https://doi.org/ 10.51599/are.2020.06.04.06 
professionals as the operators of sprinkling machines at the vocational technical institutions, do not help the increase of the efficiency of the utilization of the irrigated lands potential.

For the social economic growth of the branch did not assist such weak points of the formation of investment potential as: the drainage of wetland masses, the construction of paved roads in the countryside, the insignificant employment of population in the agricultural production. In general, the utilization of strong and weak sides of the investment potentials rose from 8.09 to 8,54 points, meaning for 5,6\% that indicates the unsatisfactory tempos of the formation of aggregate investment potential by the regions of the country, what does not assist the recovery of the agriculture form the financial economic crisis.

While analyzing the efficiency of the formation of the gross investment potential in the agriculture of Ukraine, it is necessary to separately determine the ratios of efficiency of the formation of economic, social and ecologic potentials and their average index (tabl. 2).

Table 2

The efficiency of the formation of the gross investment potential of the agriculture of Ukraine for 2014-2020 (points)

\begin{tabular}{|l|l|c|c|c|}
\hline \multirow{2}{*}{ Non } & \multirow{2}{*}{ Factors } & \multicolumn{2}{|c|}{$\begin{array}{c}\text { Rating index } \\
\text { for 2014-2020 }\end{array}$} & \multirow{2}{*}{$\begin{array}{c}\text { Ratio of the } \\
\text { efficiency } \\
\text { (un.) }\end{array}$} \\
\cline { 2 - 4 } & $\begin{array}{c}\text { Investment } \\
\text { potential }\end{array}$ & Threats & \\
\hline 1. & Economic & 6,63 & 7,54 & 0,88 \\
\hline 2. & Social & 6,38 & 8,62 & 0,74 \\
\hline 3. & Ecologic & 9,28 & 6,32 & 1,47 \\
\hline $\begin{array}{l}\text { Average factorial } \\
\text { rating index }\end{array}$ & 7,28 & 7,70 & 0,95 \\
\hline
\end{tabular}

The source: the author's own calculations

As it is shown in the table 2 the ratios of efficiency of the formation of economic and social factors have the low rating level and make respectively 0,88 and 0,74 units. The ratio of efficiency of the formation of ecologic potential is high (1,47 un.), what points out to the enhancing natural ecologic environment for the leading of the agriculture in Ukraine. In general, the average factorial index of the ratio of efficiency of the formation of the gross investment potential of the agriculture is low and makes 0,95 units.

After conducting of the analysis and the rating assessment of the formation of investment potential, we will consecutively estimate the influence of regional investment politics on the formation of investment potential and the 
attractive investment climate in the agriculture of Ukraine. Utilizing the geometric method of assessment, we will calculate the integral coefficients of economic, social and ecologic investment potentials - the stimulants and destimulants and define:

1. The integral indexes of the impact of investment politics on the formation of economic, social and ecologic investment potentials:

a) the integral meaning of the index of the impact of investment politics on the formation of economic potential (Ie.p.):

$$
\text { Ie.p. }=\sqrt[6]{3,11 \times 3,05 \times 2,11 \times 2,92 \times 2,43 \times 2,15}=\sqrt[6]{305,33}=2,59
$$

b) the integral meaning of the index of the impact of investment politics on the formation of social potential (Is.p.):

$$
I s . p .=\sqrt[3]{3,13 \times 2,24 x 1,56}=\sqrt[3]{10,94}=2,22
$$

c) the integral meaning of the index of the impact of investment politics on the formation of ecologic potential (Iecol.p.):

$$
\text { Iecol.p. }=\sqrt[3]{2,82 \times 3,12 \times 3,08}=\sqrt[3]{27,10}=3,00
$$

d) the average meaning of integral index of the impact of investment politics on the formation of economic, social and ecologic investment potentials (Iaver.p.):

$$
\text { Iaver. } p=\sqrt[3]{2,59 \times 2,22 \times 3,00}=\sqrt[3]{17,24}=2,58
$$

2. The integral indexes of the impact of investment politics on the reduction of economic, social and ecologic investment threats:

a) the integral meaning of the index of the impact of investment politics on the reduction of economic investment threats (Ie.t.):

$$
\text { Ie.t. }=\sqrt[3]{2,90 \times 2,93 \times 1,93}=\sqrt[3]{16,40}=2,54
$$

b) the integral meaning of the index of the impact of investment politics on the reduction of social investment threats (Is.t.):

$$
\text { Is.t. }=\sqrt[6]{3,10 \times 2,97 \times 2,95 \times 3,01 \times 2,79 \times 2,74}=\sqrt[6]{624.97}=2.92
$$


c) the integral meaning of the index of the impact of investment politics on the reduction of ecologic investment threats (Iecol.t.):

$$
\text { Iecol.t. }=\sqrt[5]{2,87 x 2,89 x 1,13 x 1,97 \times 3,12}=\sqrt[5]{57,61}=2,25
$$

d) the average meaning of the integral index of the impact of investment politics on the reduction of economic, social and ecologic threats (Iaver.t.):

$$
\text { Iaver.t. }=\sqrt[3]{2,54 \times 2,92 \times 2,25}=\sqrt[3]{16,69}=2,56
$$

3. The integral indexes of the efficiency of the impact of investment politics on the formation of economic, social and ecologic investment potentials:

a) the integral index of the efficiency of the impact of investment politics on the formation of economic investment potential:

$$
\text { Iec.ef. }=\frac{\sqrt[6]{3,11 \times 3,05 \times 2,11 \times 2,92 \times 2,43 \times 2,15}}{\sqrt[3]{2,90 \times 2,93 \times 1,93}}=\frac{\sqrt[6]{305,33}}{\sqrt[3]{16,40}}=\frac{2,59}{2,54}=1,02
$$

b) the integral index of the efficiency of the impact of investment politics on the formation of social investment potential:

$$
\text { Isoc.ef. }=\frac{\sqrt[3]{3,13 \times 2,24 \times 1,56}}{\sqrt[6]{3,10 \times 2,97 \times 2,95 \times 3,01 \times 2,79 \times 2,74}}=\frac{\sqrt[3]{10,94}}{\sqrt[6]{624,97}}=\frac{2,22}{2,92}=0,76
$$

c) the integral index of the efficiency of the impact of investment politics on the formation of ecologic investment potential:

$$
\text { Iecol.ef. }=\frac{\sqrt[3]{2,82 \times 3,12 \times 3,08}}{\sqrt[5]{2,87 \times 2,89 \times 1,13 \times 1,97 \times 3,12}}=\frac{\sqrt[3]{27,10}}{\sqrt[5]{57,61}}=\frac{3,00}{2,25}=1,33
$$

d) the average meaning of the integral index of the efficiency of the impact of investment politics on the formation of investment potential (economic, social, ecologic) of the agriculture:

$$
\text { Ia.ef } .=\sqrt[3]{1,02 \times 0,76 \times 1,33}=\sqrt[3]{1,03}=1,01
$$


4. The integral index of the impact of investment politics on the formation of the attractiveness of investment climate of the agriculture (IC):

$$
\mathrm{IC}=\sqrt{2,58-2,56}=\sqrt{0,02}=0,14
$$

5. The average integral index of the impact of investment politics on the formation of investment potential and the attractiveness of investment climate (Ia.p.c):

$$
\text { Ia.p.c }=\sqrt{1,01 x 0,14}=\sqrt{0,14}=0,38
$$

From the received mathematic calculations is evident that the high level of investment threats and the low level of social investment potential negatively influenced the integral index of the formation of investment potential and the investment attractiveness of the investment climate of the agriculture.

\section{CONCLUSIONS}

Considering this, it is necessary to direct the regional investment politics of the state to more powerful utilization of the opportunities and the threats reduction that contains the use of economic, social and ecologic resources. The results of conducted analysis indicate that the agriculture has the significant opportunities for more efficient utilization of the resource potential by means of:

- the resumption of land resources fertility (the consumption of the optimal amount of fertilizers, the utilization of ecologically safe technologies);

- the increase of the volumes of capital investments (the resumption of irrigating chains, the renewal of technical means, the building of storage and processing capacities);

- the growth of export of the agrarian output (first of all the organic and processed food);

- the enhancement of labor productivity (by means of the innovative technologies and the highly-qualified professionals);

- the improvement of financial results (the production of output with the high added value, the utilization of the power-saving technologies, the improvement of the quality of plough-lands);

- the increase of the level of health care of the rural population.

The significant level of investment threats reduces the efficiency of the formation of investment potential of the branch. The level of average integral assessment of the efficiency of the formation of investment potential and the investment climate of the agriculture is estimated as being crisis. 
Considering that the aims and purpose of investment politics of 2013-2020 are partially attained, and the integral assessment of the efficiency of the impact of regional investment politics of the agriculture development on the formation of investment potential and the investment climate of the branch are defined as being crisis $(0,38$ un.), we estimate its general influence on the social ecologic development of the agriculture as being insufficiently effective.

The strategy of the management of ecological security in the agrarian sector should consider such factors as the scientifically rigorous land use, the utilization of innovative technologies of soil cultivation, the reasonable exploitation of water resources for the irrigation of agricultural crops, the consumption of optimal norms of mineral fertilizers that do not affect the health of people and others. The investment of measures, which are directed to the environmental protection and improvement of ecological security of population, gives an opportunity to eliminate the contradictions that appear between the economic development of the region and its social ecological consequences.

Therefore, the main aim of investment politics of the regional development of the agriculture should be not only the preservation of water and land resources, but also the increase of the level of their natural value, that is the determinant of the attractiveness of agrarian sector of economics for the investors and the improvement of the quality of livelihood of the rural population.

\section{SUMMARY}

The methodic approaches to the estimation of the efficiency of regional investment politics of the agriculture formation were determined. The algorithm of determination of the estimation of efficiency of the regional investment politics influence on the development of agriculture of Ukraine was suggested. The aim and goals of investment politics have to be real, have strategic perspective, be oriented to more rational usage of financialeconomic, social, natural-resource and industrial opportunities while meeting current and long-term challenges of the social-economic development.

\section{REFERENCES}

1. Polshakova V.I. (2009). Investment management. "Kondor". Ukraine.

2. Goncharenko I.V., Tanklevska N.S. (2010). Methodical approaches to the implementation of the budgeting system at enterprises. Bulletin of Sumy National Agrarian University. 5/2 (40). 64-68. Ukraine.

3. Orlovskaya Y.V. (2006). Strategy of investment management in regional development. Knowledge of Ukraine.

4. Grinyova V.M., Koyuda V.O. (2004). Finance of enterprises (2nd ed). Knowledge. Press. 
5. Prikhodko I.P. (2004). The efficiency of personal peasant farms. State and Regions. Series: economics and entrepreneurship. 2. 123-125.

6. Petina L.V. (2015). Leasing - an innovative factor in activating investment processes in agriculture. Economics. Finances. Jurisprudence. Kyiv. 7. 4-7.

7. Petina L.V. (2010). Directions of growth of investment potential of agrarian enterprises. Tavriya Scientific Bulletin. Kherson. 81. 395-399.

8. Onishko S.V. (2007). State regulation of the national economy. Irpin: National University of the State Tax Service of Ukraine.

9. Karnaushenko, A., Petrenko, V., Tanklevska, N., Borovik, L., \& Furdak, M. (2020). Prospects of youth agricultural entrepreneurship in Ukraine. Agricultural and Resource Economics: International Scientific E-Journal, 6(4), 90-117. DOI: https://doi.org/10.51599/are.2020.06.04.06

\section{Information about the author:} Borovik Liubov Volodymyrivna, Doctor of Economics, Associate Professor, Associate Professor at the Department of Economic and Finance Kherson State agrarian and economic University 23, Stritenska str., Kherson, Ukraine, 73006 orcid.org/0000-0001-7200-0497 